\title{
Risk Factors for Frequency of Readmission Among Heart Failure Patients
}

\author{
Nour Eleman Hassan Ali ${ }^{1}$, Shalabia El-Sayead Abozead ${ }^{2}$, Ahmed Abdel Galeel Ahmed ${ }^{3}$ \& Hanan Abd El- \\ Razik Abd El-All ${ }^{4}$. \\ ${ }_{1}^{1}$ Assistant Lecturer of Medical Surgical Nursing, Faculty of Nursing, Assiut University, Assiut, Egypt. \\ ${ }^{2}$ Professor of Medical Surgical Nursing, Faculty of Nursing, Assiut University, Assiut, Egypt. \\ ${ }^{3}$ Assistant Professor of Cardiology, Faculty of Medicine, Assiut University, Assiut, Egypt. \\ ${ }^{4}$ Assistant Professor of Medical Surgical Nursing, Faculty of Nursing, Assiut University, Assiut, Egypt.
}

\begin{abstract}
The aim of the study was to identify risk factors for frequency of readmission among heart failure patients at Assiut University Hospital. Research design: A descriptive exploratory research design was utilized to conduct this study. Setting: This study was carried out in the cardiovascular medicine department at Assiut University Hospital. sample: The study sample consists of a (100) heart failure patients; ages ranged from 18-65 years old. Tools: Two tools were used; tool one: a patient assessment sheet, tool two: re-admission assessment sheet. Results: Frequency of patients' readmission in a period of (6) months was (31\%), (64.5\%) have readmitted once, $(29.03 \%)$ twice and (6.45\%) three times. Highest percent was readmitted within 60 days of discharge (38.7\%), (19.4\%) readmitted within 30 days of discharge and (19.4\%) readmitted within 90 days of discharge. Drug non-compliance, diet poor compliance, uncontrolled diabetes mellitus, ischemia, anemia and worsening left ventricular function were the major risk factors for HF patients'readmission. Conclusion: Frequency of patients' readmission was (31\%). Drug non-compliance, diet poor compliance, uncontrolled diabetes mellitus, ischemia, anemia and worsening left ventricular function were the major risk factors for HF patients 'readmission. Recommendations: Design educational programs for patients with HF to reduce frequency of readmission of those patients.
\end{abstract}

\section{Keywords: Frequency, Heart Failure \& Readmission.}

\section{Introduction}

Heart failure (HF) is a clinical syndrome that commonly occurs due to a structural or functional damage of the heart muscle so that the heart can't pump enough blood to meet the body's needs (Ralston et al., 2018).

Congestive heart failure (CHF) is a cumulative cardiovascular disease with significant morbidity and mortality that affects an increasing amount of people worldwide. There are about 6.5 million people in the United States, more than (14) million people in Europe, and (26) million people worldwide who are living with heart failure, and the prevalence continues to grow (Benjamin et al., 2017).

In Egypt, Saudi Arabia and United Arab Emirates about 1.35 million patients are being treated for $\mathrm{HF}$, $(E G=931,135 ; \mathrm{SA}=320,933 ; \mathrm{UAE}=93,865)$. The total estimated costs are US $\$ 1.92$ Billion $(\mathrm{EG}=\$ 0.356 \mathrm{~B}$; $\mathrm{SA}=\$ 1.045 \mathrm{~B} ; \mathrm{UAE}=\$ 0.519 \mathrm{~B})$. Annual per-patient costs were highest in UAE followed by SA and EG (US \$13,836; \$8,137; \$850, respectively). Inpatient admission cost was the major cost driver ranging from $25 \%$ to $56 \%$ (AlHabeeb et al., 2018).

There are several HF risk factors which have been reported in the last decades including age, sex, coronary artery disease (CAD), myocardial infarction (MI), hypertension, diabetes mellitus, and obesity as the most important risk factors, In turn, some of HF risk factors, such as CAD and MI, are explained by several established cardiovascular (CV) risk factors, such as diet, sedentary lifestyle, and smoking (Meijers \& de Boer, 2019).

Hospital admission due to worsened HF is a very important dimension of the clinical practice of patients with HF. Furthermore, patients with worsened HF are frequently admitted to the hospital after the onset of HF (Alcober-Morte et al., 2019). Among patients with chronic HF in the United States, the proportion of readmission within 6 months after hospital discharge was reported to be $\sim 50 \%$. Previous studies have shown that a prior history of hospitalization was associated with a poor clinical outcome in patients with HF (Ziaeian and Fonarow, 2016).

Readmission from HF is considered as an important contributory cause of high hospital expenditure. comorbid conditions (such as diabetes mellitus, history of ischemic heart disease, anemia, depression, atrial fibrillation and chronic kidney disease), worsening renal function, elevated cardiac troponin and prolonged hospital stay have been identified as potential predictors for frequent readmissions (Wang et al., 2019). 
Nurses as main members of the health care team, should have a suitable understanding of continuous care programs. This may help them to play a critical role in development of strategies for follow-up and continuous care to prevent readmissions, effective using of resources and reducing the costs. However, in most countries taking care of patients with HF has been limited to hospitals or just some training before discharge from hospital. Although there are some researches about the effects of post discharge continuous home care (Chen et al., 2012).

\section{Significance of the study}

From the researcher's review of literatures it was found that $\mathrm{HF}$ continues to increase in prevalence with a great impact on morbidity and mortality in addition to patients who suffer from HF often experience a decline in health resulting in recurrent hospitalizations and debilitating symptoms. This vulnerable population and the epidemic growth of heart failure with repeated readmissions have created a significant interest in collecting data that might help in planning and implementing further nursing studies for such group of patients with the goal of reducing cyclic readmissions to the hospital.

\section{The aim of the study}

The aim of this study was to identify risk factors for frequency of Readmission among Heart Failure Patients at Assiut University Hospital.

\section{Research question}

What are risk factors for frequency of Readmission among Heart Failure Patients at Assiut University Hospital?

\section{Subjects and Methods}

\section{Research design:}

A descriptive exploratory research design was utilized to conduct this study.

\section{Setting}

This study was conducted in the Cardiovascular Medicine Department at Al-Orman University Hospital for Cardiology/ Assiut University Hospital. sample:

The study sample consists of a (100) heart failure patients; ages ranged from 18-65 years old from both sex and agreed to participate in the study.

\section{Study tools}

In order to collect the necessary information for this study, the following tools were used:

\section{Tool (I): Patient assessment sheet:}

It was developed by the researcher based on national and international literature review (Xexemeku et al., 2014), (Deek et al., 2016) under guidance of supervisors and it divided into two parts: -

Part 1: Demographic data of the patient: This part aimed to assess data such as (age, gender, marital status, level of education, occupation, date of admission and date of discharge (length of stay).

Part 2: Medical data assessment: This part was developed to assess

Patients medical history as duration of heart failure disease and risk factors for HF involving, presence of diabetes mellitus, hypertension, ischemic heart disease, dyslipidemia and arrhythmia as atrial fibrillation. Also, history of risk factors such as smoking would be inquired. History of renal troubles, thyroid dysfunction or advanced chest disease will be added.

Tool (II): Re-admission assessment tool: This tool was developed by the researcher based on national and international literature review (Deek et al., 2016), (Wang et al., 2017), and opinions of the medical \& nursing expertise to assess the frequency and causes (risk factors) of hospital re-admission for heart failure patients for 6 months following discharge and contained the following items:

1- $\quad$ Frequency of readmissions per 6 months (once, twice, three times, four times, five times...etc.) 2- $\quad$ Period from discharge to readmission in days (mean $\pm \mathrm{SD})$.

a-Period from discharge to $1^{\text {st }}$ readmission in days (mean $\pm \mathrm{SD})$.

b- Period from discharge to 2 nd readmission in days (mean $\pm \mathrm{SD}$ ).

c- Period from discharge to 3 rd readmission in days (mean \pm SD).

3- Risk factors for re-admission: (uncontrolled diabetes mellitus, Uncontrolled blood pressure, CAD and dyslipidaemia), chest infection or any other infection, anaemia, non-compliance with medication, poor compliance with diet regimen, Worsening left ventricular function, Hypoxemia, Ischemia.

\section{Methods of data collection}

An official approval \& administration permission to conduct this study was obtained from the head of cardiovascular department, the aim of the study was explained to them to obtain their cooperation. This study was implemented through four phases:

\section{Preparatory phase}

It included reviewing of the national and international related literature in the various aspects of the problem using books, articles, periodicals, and magazines to develop the study tools for data collection, the content validity for the designed tools was judged by jury of expertise (three supervisors of medicine and medical surgical nursing at Assiut university) who reviewed the tools of data collection for clarity, relevance, comprehensiveness, understanding, applicability and easiness. 
2- Exploratory phase: (Pilot study)

This phase is done to ensure the test reliability; the researcher followed test/retest technique. The researcher applied it to a pilot sample of $10 \%$ (10) patients who were included in the main study as there were no modifications. The reliability of the test was calculated by using correlation coefficient and it was estimated by Alpha Cronbach's test for this study.

\section{3- Planning phase}

Based on finding of the jury\& exploratory phase, the study tools for data collection were developed.

4- Implementation phase

- Oral consent was obtained from patients or guidance who were willing to participate in the study, after explaining the nature and purpose of the study.

- Participant patients were interviewed by the researcher to fill in the tools sheet.

- The interview method was used to collect the necessary data for this study.

- Every patient was interviewed for two times.

- The first-interview was used to collect the base line assessment data using the first tool (Patient assessment sheet).

- The Second interview was carried out for readmitted heart failure patients for 6 months following patient discharge by follow up through telephone calls then meetings for interview the patient using the second tool (Re-admission assessment tool) to assess the frequency and causes of hospital re-admission of heart failure patients.

- Data were collected from Cardiovascular Medicine Department at Al-Orman University Hospital for Cardiology/ Assiut University Hospital during the period from March 2019 to February 2020.

\section{Ethical considerations}

- Permission to carry out the study was obtained from Ethical Committee in the Faculty of Nursing.

- An official approval \& administration permission to conduct this study was obtained from the head of cardiovascular department.

- Oral consent was obtained from patients or guidance who were willing to participate in the study, after explaining the nature and purpose of the study.

- There is no risk for study subject during application of the research.

- The study will follow common ethical principles in clinical research.
- Confidentiality and anonymity were assured.

- Patients have the right to refuse to participate and or withdraw from the study without any rational any time.

\section{Statistical analysis}

Data were verified, coded by the researcher, and analysed using IBM-SPSS 21.0 (IBM-SPSS Inc., Chicago, IL, USA) *. Descriptive statistics: Means, standard deviations and percentages were calculated. Chi-square test was used to compare between qualitative variables. P-value considered statistically significant when $\mathrm{P}<0.05$. 


\section{Results}

Table (1): Frequency distribution of the studied sample according to demographic characteristics $(n=100)$.

\begin{tabular}{|c|c|c|}
\hline Items & No & $\%$ \\
\hline \multicolumn{3}{|l|}{ Age group in years: } \\
\hline Less than 30 years & 3 & 3.0 \\
\hline from $30-40$ years & 8 & 8.0 \\
\hline from $40-50$ years & 15 & 15.0 \\
\hline more than 50 years & 74 & 74.0 \\
\hline Range & \multicolumn{2}{|c|}{$18-65$} \\
\hline Mean \pm SD & \multicolumn{2}{|c|}{$55.7 \pm 10.5$} \\
\hline \multicolumn{3}{|l|}{ Sex: } \\
\hline Male & 75 & 75.0 \\
\hline Female & 25 & 25.0 \\
\hline \multicolumn{3}{|l|}{ Marital status: } \\
\hline Un married & 12 & 12.0 \\
\hline Married & 88 & 88.0 \\
\hline \multicolumn{3}{|l|}{ Educational level: } \\
\hline Non- Educated & 46 & 46.0 \\
\hline Educated & 54 & 54 \\
\hline \multicolumn{3}{|l|}{ Occupation: } \\
\hline Employed & 19 & 19.0 \\
\hline Unemployed & 81 & 81.0 \\
\hline \multicolumn{3}{|l|}{ Length of stay: } \\
\hline Range & \multicolumn{2}{|c|}{$2-54$} \\
\hline Mean \pm SD & \multicolumn{2}{|c|}{$10.48 \pm 8.62$} \\
\hline
\end{tabular}

Table (2): Frequency distribution of the studied sample according to risk factors for heart failure $(n=100)$.

\begin{tabular}{|c|c|c|}
\hline Items & No & $\%$ \\
\hline \multicolumn{3}{|l|}{ Hypertension: } \\
\hline Yes & 35 & 35.0 \\
\hline No & 65 & 65.0 \\
\hline \multicolumn{3}{|l|}{ Ischemic heart disease: } \\
\hline Yes & 41 & 41.0 \\
\hline No & 59 & 59.0 \\
\hline \multicolumn{3}{|l|}{ Diabetes: } \\
\hline Yes & 41 & 41.0 \\
\hline No & 59 & 59.0 \\
\hline \multicolumn{3}{|l|}{ Arrhythmia as atrial fibrillation: } \\
\hline not present & 100 & 100.0 \\
\hline \multicolumn{3}{|l|}{ Dyslipidemia: } \\
\hline Yes & 3 & 3.0 \\
\hline No & 97 & 97.0 \\
\hline \multicolumn{3}{|l|}{ History of renal troubles: } \\
\hline Yes & 1 & 1.0 \\
\hline No & 99 & 99.0 \\
\hline \multicolumn{3}{|l|}{ Thyroid dysfunction: } \\
\hline Yes & 4 & 4.0 \\
\hline No & 96 & 96.0 \\
\hline \multicolumn{3}{|l|}{ Advanced chest disease (COPD): } \\
\hline not present & 100 & 100.0 \\
\hline
\end{tabular}




\begin{tabular}{|l|c|c|}
\hline \multicolumn{1}{|c|}{ Items } & No & \% \\
\hline Smoking: & 60 & 60.0 \\
\hline Yes (from 75 male) & 40 & 40.0 \\
\hline No & \multicolumn{2}{l|}{} \\
\hline Duration of heart failure: & 35 & 35.0 \\
\hline$<1$ year & 37 & 37.0 \\
\hline $1-5$ years & 19 & 19.0 \\
\hline 5-10 years & 9 & 9.0 \\
\hline$>10$ years & 9 & \\
\hline
\end{tabular}

Table (3): Readmission assessment data of studied patients $(n=100)$.

\begin{tabular}{|c|c|c|}
\hline Items: & NO & $\%$ \\
\hline \multicolumn{3}{|c|}{ Frequency of patient readmissions in a period of 6 months: } \\
\hline No: & 69 & 69.0 \\
\hline Yes: & 31 & 31.0 \\
\hline If yes, Once & 20 & 64.5 \\
\hline Twice & 9 & 29.03 \\
\hline three times & 2 & 6.45 \\
\hline \multicolumn{3}{|c|}{ period from discharge to $1^{\text {st }}$ readmission within days: } \\
\hline 30 days & 6 & 19.4 \\
\hline 60 days & 12 & 38.7 \\
\hline 90 days & 6 & 19.4 \\
\hline 120 days & 3 & 9.7 \\
\hline 150 days & 3 & 9.7 \\
\hline 180 days & 1 & 3.2 \\
\hline Mean \pm SD $($ range $)$ & \multicolumn{2}{|c|}{$65.81 \pm 40.28(15-163)$} \\
\hline \multicolumn{3}{|c|}{ period from discharge to 2nd readmission within days: } \\
\hline 30 days & 3 & 27.3 \\
\hline 60 days & 7 & 63.6 \\
\hline 90 days & 1 & 9.1 \\
\hline Mean \pm SD $($ range $)$ & \multicolumn{2}{|c|}{$42.55 \pm 15.91(17-65)$} \\
\hline \multicolumn{3}{|c|}{ period from discharge to 3rd readmission within days: } \\
\hline 60 days & 2 & 100.0 \\
\hline Mean \pm SD (range) & \multicolumn{2}{|c|}{$39 \pm 9.9(32-46)$} \\
\hline \multicolumn{3}{|l|}{ Mortality: } \\
\hline No & 70 & 70.0 \\
\hline Yes & 30 & 30.0 \\
\hline
\end{tabular}

Table (4): Frequency distribution for Readmission risk factors of studied patients $(\mathrm{n}=\mathbf{1 0 0})$.

\begin{tabular}{|l|c|c|}
\hline \multicolumn{1}{|c|}{ Items: } & No & $\%$ \\
\hline Drug Non-compliance & 8 & 25.8 \\
\hline Diet Poor compliance & 7 & 22.6 \\
\hline Uncontrolled Diabetes Mellitus & 7 & 22.6 \\
\hline Ischemia & 6 & 19.4 \\
\hline Anemia & 5 & 16.1 \\
\hline Worsening Left Ventricular Function & 5 & 16.1 \\
\hline Hyperlipidemia & 3 & 9.7 \\
\hline Uncontrolled Blood Pressure & 2 & 6.5 \\
\hline Infection (Chest or Other) & 2 & 6.5 \\
\hline Coronary artery disease & 0 & 0.0 \\
\hline Hypoxemia & 0 & 0.0 \\
\hline Others & 10 & 32.3 \\
\hline
\end{tabular}


Table (1): Shows that the highest percent of the studied sample were male $(75 \%)$, their age more than 50 years $(74 \%)$, married $(88 \%)$, educated $(54 \%)$ and unemployed $(81 \%)$.

Table (2): Shows that the highest percent of the studied sample were smokers $(60 \%)$, having hypertension (35\%), ischemic heart disease (41\%) and diabetes $(41 \%)$, the highest percent of their duration of heart failure from 1-5 years $(37 \%)$, then < 1 year (35\%).

Table (3): Illustrates that the frequency of patients' readmission in a period of 6 months was $(31 \%)$, of them $(64.5 \%)$ have readmitted once, $(29.03 \%)$ have readmitted twice, $(6.45 \%)$ have readmitted three times, of them the highest percent was readmitted within 60 days of discharge $(38.7 \%)$, (19.4\%) readmitted within 30 days of discharge and (19.4\%) readmitted within 90 days of discharge.

Table (4): Clarifies that the highest percent of risk factors for readmitted patients were drug noncompliance $(25.8 \%)$, diet poor compliance $(22.6 \%)$, uncontrolled diabetes mellitus $(22.6 \%)$, ischemia $(19.4 \%)$, anemia $(16.1 \%)$ and Worsening Left Ventricular Function (16.1\%).

\section{Discussion}

Regarding the demographical data, the majority of the patients $(75 \%)$ were males, with a mean age of $55.7 \pm 10.5$ years (range 18-65). This study finding was in line with a study by (Sulaiman et al., 2015) which revealed that; the majority of the patients $(63 \%)$ were males, with a mean age of $59 \pm 15$ years. Also, agree with (Bradford et al., 2017) who found that the study sample predominantly male $(55 \%)$ which is agree with our findings. Also, (Yang et al., 2015) who proved that from the strongest independent associations for incident HF were age and male gender.

According to medical history, highest percent of the studied sample were smokers $(60 \%)$, having hypertension (35\%), ischemic heart disease (41\%) and diabetes (41\%). This study findings agree with a study by (Sulaiman et al., 2015) which revealed that Co-morbid conditions were common with heart failure, particularly hypertension, diabetes mellitus, Coronary artery disease, and hyperlipidaemia. Also, agree with (Yang et al., 2015) who proved that the strongest independent associations for incident $\mathrm{HF}$ were coronary artery disease, diabetes mellitus, followed by hypertension and smoking. Also, the result of this study was in line with a study by (Arora et al., 2017) who found that diabetes mellitus is present in $39 \%$ to $42 \%$ of patients with HF. and is known to be an independent risk factor for the development of $\mathrm{HF}$.
This study explored that out of the (100) patients admitted in 2019 in the Cardiovascular Medicine Department at Al-Orman University Hospital for Cardiology/ Assiut University Hospital, there were (31) patients (31\% of the sample) readmitted within a period of 6 months of their index discharge. Of the $31,20(64.5 \%)$ were readmitted once, $9(29.03 \%)$ were readmitted twice, $2(6.45 \%)$ were readmitted three times. Six patients $(19.4 \%)$ were readmitted within 30 days of the index discharge, $12(38.7 \%)$ within 60 days and 6 (19.4\%) within 90 days. This study finding was in line with a study by (Deek et al., 2016) which found that out of the (187) patients, there were (72) patients (38.5\% of the sample) readmitted within 90 days of their index discharge. Of the 72 patients, 52(72.2\%) were readmitted once, $16(22.2 \%)$ were readmitted twice, three $(4.17 \%)$ were readmitted three times and one (1.39) was readmitted four times. Twenty-eight patients $(15 \%)$ were readmitted within 30 days of the index discharge, $42(22.5 \%)$ within 60 days and $52(27.8 \%)$ within 90 days. From the researcher's opinion, this reduction in readmission because of the large percent of mortality (30\%) within follow up period in this study.

When looking at risk factors for readmission of HF patients, we found that the highest percent of risk factors for readmitted patients were drug noncompliance $(25.8 \%)$, diet poor compliance $(22.6 \%)$, uncontrolled diabetes mellitus (22.6\%), ischemia (19.4\%), anemia (16.1\%) and worsening left ventricular function $(16.1 \%)$. This study findings was supported by (Annema et al., 2009) who observed that from the reasons for readmission worsening HF and other factors, such as comorbidity, nonadherence, and nonoptimal medication, were important contributing factors. Also, agree with (Su et al., 2019) who found that from the Clinical risk factors associated with heart failure readmissions comorbidities such as diabetes mellitus and anemia. There is difference in risk factors for HF patient's readmission in multiple studies according to studied patients' characteristics. In this study, from the researcher's point of view the founded risk factors because of reduced their knowledge about their disease and their medications that's related to the large percent of non-educated patients (46\%) in this study and because their low socio-economic status. There is also, lack of patient education about heart healthy living.

\section{Conclusion}

Finally, we conclude that the majority of the patients were males, with a mean age of $55.7 \pm 10.5$ years (range 18-65). Smoking, ischemic heart disease, diabetes, hypertension, were the major risk factors for HF respectively. The Frequency of patients' 
readmission in a period of 6 months was (31\%), of them $(64.5 \%)$ have readmitted once, $(29.03 \%)$ have readmitted twice, $(6.45 \%)$ have readmitted three times, of them the highest percent was readmitted within 60 days of discharge (38.7\%), (19.4\%) readmitted within 30 days of discharge and (19.4\%) readmitted within 90 days of discharge. Drug noncompliance, diet poor compliance, uncontrolled diabetes mellitus, ischemia, anemia and Worsening Left Ventricular Function were the major risk factors for HF patients 'readmission respectively.

\section{Recommendations}

1- Life style modification programs for modifying risk factors leading to $\mathrm{HF}$.

2- Design educational programs for patients with $\mathrm{HF}$ to reduce frequency of readmission of those patients.

\section{References}

1 Alcober-Morte, L., Barrio-Ruiz, C., ParelladaEsquius, N., Subirana, I., Comín-Colet, J., Grau, M., \& Mestre-Ferrer, J., (2019): Heart failure admission across glomerular filtration rate categories in a community cohort of 125,053 individuals over 60 years of age. Hypertension Research, Vol. (42), No. (12), P.P. 2013-2020.

2 AlHabeeb W., Akhras K., AlGhalayini K., AlMudaiheem H., Ibrahim B., Lawand S., \& Bader F., (2018): Understanding Heart Failure Burden in Middle East Countries: Economic Impact in Egypt, Saudi Arabia and United Arab Emirates. Value in Health, Vol. (21), No. (1), p.123.

3 Annema C., Luttik M., \& Jaarsma T., (2009): Reasons for readmission in heart failure: perspectives of patients, caregivers, cardiologists, and heart failure nurses. Heart \& Lung, Vol. (38), No. (5), P.P.427-434.

4 Arora S., Patel P., Lahewala S., Patel N., Patel N., Thakore K., \& Shah M., (2017): Etiologies, trends, and predictors of 30-day readmission in patients with heart failure. The American journal of cardiology, Vol. (119), No. (5), p.p. 760-769.

5 Benjamin E., Blaha M., \& Chiuve S., (2017): Heart disease and stroke statistics -2017 update: a report from the American Heart Association, Circulation, Vol. 135, P.P. 146-603.

6 Bradford C., Shah B., Shane P., Wachi N., \& Sahota K., (2017): Patient and clinical characteristics that heighten risk for heart failure readmission. Research in Social and Administrative Pharmacy, Vol. (13), No. (6), P.P. 1070-1081.
7 Chen J., Ross J., Carlson M., Lin Z., Normand S., Bernheim S., \& Krumholz H., (2012): Skilled nursing facility referral and hospital readmission rates after heart failure or myocardial infarction. The American journal of medicine, Vol. (125), No. (1), P.P. 1-9.

8 Deek H., Skouri H., \& Noureddine S., (2016): Readmission rates and related factors in heart failure patients: A study in Lebanon, Collegian Vol. (23), No. (1), p.p. 61- 68.

9 Meijers W., \& de Boer R., (2019): Common risk factors for heart failure and cancer, Cardiovascular Research, Vol. (115), No. (5), p.p. 844-853.

10 Ralston S., Penman I., Strachan M., \& Hobson R., (2018): Cardiovascular disease, Presenting problems in cardiovascular disease, Heart failure, Ch. 18, Davidson's Principles and Practice of Medicine, $23_{\text {rd }}$ ed., Elsevier, p. 543.

11 Su A., Al'Aref S., Beecy A., Min J., \& Karas M., (2019): Clinical and socioeconomic predictors of heart failure readmissions: A review of contemporary literature, Elsevier, In Mayo Clinic Proceedings Vol. (94), No. (7), p.p. 1304-1320.

12 Sulaiman K., Panduranga P., Al-Zakwani I., Alsheikh-Ali A., AlHabib K., Al-Suwaidi J., \& Ridha M., (2015): Clinical characteristics, management, and outcomes of acute heart failure patients: observations from the Gulf acute heart failure registry (Gulf CARE). European Journal of Heart Failure, Vol. (17), No. (4), p.p.374-384.

13 Wang N., Gallagher R., Sze D., Hales S., \& Tofler G., (2017): Predictors of Frequent Readmissions in Patients with Heart Failure, Heart, Lung and Circulation, Vol. (25), No. (2), p.p.118- 119 .

14 Wang N., Gallagher R., Sze D., Hales S., \& Tofler G., (2019): Predictors of Frequent Readmissions in Patients with Heart Failure, Heart Lung Circ., Vol. (28), No. (2), p.p. 277-283.

15 Xexemeku F., Singh A., Adjepong Y., \& Zarich S., (2014): Predictors of Early Readmission in Heart Failure Patients in an Inner-City Community Hospital, World Journal of Cardiovascular Diseases, Vol. 4, No. (9), p.p. 476482.

16 Yang H., Negishi K., Otahal P., \& Marwick T., (2015): Clinical prediction of incident heart failure risk: a systematic review and metaanalysis. Open heart, Vol. (2), No. (1). e000222.

17 Ziaeian B., \& Fonarow G., (2016): The prevention of hospital readmissions in heart failure. Progress in cardiovascular diseases; Vol. (58), No. (4), P.P. 379-385. 